\title{
EMANCIPACIÓN, DESCOLONIZACIÓN Y USO DEL DERECHO
}

\section{EMANCIPATION, DECOLONIZATION AND USE OF LAW}

\author{
Daniel J. García-López \\ Universidad de Granada \\ danieljgl@ugr.es \\ https://orcid.org/0000-0003-0601-1395 \\ Luísa Winter-Pereira \\ Universidade de Coimbra \\ luisa.w.pereira@gmail.com \\ https:/orcid.org/0000-0003-3775-9742
}

\begin{abstract}
Resumen
En el presente artículo defendemos la proposición de que el derecho, surgido a partir del siglo XVI (con la conjunción de Estado, capitalismo y sujeto), mantiene una raíz eminentemente colonial, por lo que su objetivo es su propia expansión. Proponemos el término matriz de inteligibilidad jurídico-colonial para explicar cómo se produce una naturalización del fenómeno jurídico para construir la ficción de su universalidad y su atemporalidad. A partir de esta concepción del derecho, nos planteamos el lugar que ocupa la subjetividad en la pregunta por la emancipación y la descolonización, concluyendo con la necesidad de pensar la categoría uso como línea de fuga de la matriz de inteligibilidad jurídico-colonial.
\end{abstract}

Palabras clave: Colonialidad del derecho; Descolonización; Emancipación; Matriz de inteligibilidad jurídico-colonial; Subjetividad; Uso

\begin{abstract}
In this paper we defend the proposition that the law, which has emerged since the 16th century (in conjunction with State, capitalism and subject), maintains an eminently colonial root and has as its objective its own expansion. We propose the term matrix of legalcolonial intelligibility to explain how a naturalization of the legal phenomenon is produced and used to construct the fiction of its universality and its timelessness. From this concept of law, we consider the place of subjectivity in the question of emancipation and decolonization, concluding with the need to think of the category "use" as a line of escape from the matrix of legal-colonial intelligibility.
\end{abstract}

Keywords: Coloniality of law; Decolonization; Emancipation; Matrix of Legal-Colonial Intelligibility; Subjectivity; Use. 


\section{Introducción}

"El proceso somete a confrontación a dos mundos diferentes. Recompone la vida bajo la forma de la legalidad. No, no es posible. Cheese, cheese. Hasta ellos saben que no es posible. Por eso todo lo que rodea el proceso carece de cualquier racionalidad. Las jaulas, las esposas, las horas y horas de celda. No, no quieren la verdad, sino el rito. El sacrificio. La legalidad se restaura en lo simbólico, no en lo racional". (Negri, 1990: 22)

El derecho necesita del ritual y del sacrificio. Y, en ocasiones, aquel que es situado en el altar sacrificial es el propio derecho. Toni Negri escribía aquellas palabras durante su cautiverio en prisión esperando sentencia en el maxi-proceso 7 aprile contra Autonomia Operaia. Eran los años de plomo, la estrategia de la tensión provocada desde las élites económico-políticas contra cualquier espacio de crítica y resistencia.

En el bienio 1968-1969 las protestas estudiantiles y obreras ocuparon los rotativos italianos $^{1}$. Los movimientos de izquierdas se rearmaron. No solo en la calle, también en las salas judiciales. Aquel 1968 supuso la irrupción de una corriente crítica con el derecho. En 1972, en Catania se reunieron profesores y magistrados para reflexionar sobre el papel de la judicatura. De ahí vino a llamarse uso alternativo del diritto (Barcellona, 1973) a la traducción de la lucha de clases en el marco del derecho, para devolver la dignidad a los sujetos excluidos por medio de la reapropiación social de la función normativa (Barcellona y Cotturi, 1976: 262-263). Por medio de la interpretación judicial y más allá del fetichismo de la ley, pretendían realizar un cambio social a través del conflicto capital-trabajo llevado a los tribunales. Pero ya a mediados de la década de los 70 , los alternativistas se dividieron entre quienes pretendían el cambio social por medio de la conciliación/neutralización y quienes lo hacían por medio del conflicto (Silveira Gorski, 1998: 78-79).

Como consecuencia del clima de conflicto de los 70 , la neutralización por parte del Gobierno se realizó por medio de la estrategia de los derechos: una serie de reformas que restituyeron derechos a la ciudadanía, especialmente en el ámbito penal (asistencia de abogacía defensora en los interrogatorios, limitación de la prisión preventiva) y laboral (Estatuto de los trabajadores) (Silveira Gorski, 1998: 85-86). Pero si la Guerra Fría se había instalado en el interior de Italia, también lo hicieron los postulados de la Comisión Trilateral sobre la gobernabilidad en las democracias occidentales (Capella, 2005: 91-95). La tesis que defendía el informe de 1975 era sencilla: más democracia supone mayor riesgo de amenazas internas. ¿Cómo solucionarlo? Poniendo límites a la democracia del Estado social.

Comienza la strategia della tensione. La extrema derecha siembra el horror por medio de innumerables atentados, la mafia continúa con sus affaire, el Estado responde con autoritarismo con la emergencia como forma de gobierno. Así se pone fin a la estrategia de los derechos por medio de un derecho especial de policía. Con las Leyes Bartolomei y Reale se ampliaron los poderes de la policía hasta el punto de poder interrogar sin presencia de abogacía o detener y registrar sin orden judicial. De ahí que el sistema penal de emergencia rompiera con las reglas del Estado de Derecho, actuando de forma pre-delictual (Ferrajoli, 1989: 855).

Lo que nos muestra el laboratorio italiano es cómo desde dentro del propio derecho se ha tratado de realizar una resignificación que ha desembocado en sangre

1 Recuerden aquí las críticas que hizo Pasolini al movimiento estudiantil y su aburguesamiento (Pasolini, 2010: 5-11). 
derramada. Quienes poseen históricamente los medios de producción jurídica y del sentido mismo del derecho, neutralizan y eliminan cualquier atisbo de un uso alternativo. Pero lo cierto es que aquel intento italiano se realizó por sujetos que contaban para el sistema jurídico -en tanto sus condiciones materiales eran privilegiadas- haciendo imposible que el derecho fuera apropiado por la clase obrera. De este laboratorio italiano podemos extraer aprendizajes para elaborar mejor la estrategia, porque en Italia encontramos los experimentos jurídicos que el neoliberalismo luego ensayó principalmente en Latinoamérica.

Lo que aquí quisiéramos reflexionar, desde las coordenadas trazadas en esta introducción, es si es posible la reapropiación de los dispositivos de producción jurídica desde no-sujetos. Es así que en el primer epígrafe nos detendremos en cómo ha sido planteada la pregunta por la relación entre derecho y emancipación. En el siguiente epígrafe completaremos esta pregunta situando en el centro la subjetividad, pues quizás no se trate tanto de las características que deba tener esa emancipación sino desde dónde -un dónde en tanto quién- se ha de realizar. A continuación, nos plantearemos cómo entendemos que el derecho emerge en un determinado momento asociado a la colonización y cómo esta dependencia será encubierta por medio de una matriz de inteligibilidad. Finalmente, concluiremos con una propuesta para pensar cómo salir de la colonialidad jurídica a partir de la categoría uso.

\section{La pregunta por el carácter emancipatorio del derecho}

Si en la Italia sometida a la estrategia de la tensión se produjo un intento por un uso alternativo del derecho, ¿qué ocurre en otros espacios geo-jurídicos en los que existe una estrategia similar? Pensemos en América Latina². Como señaló Walter Mignolo, si América fue una invención europea moderna basada en la visión limitada que los europeos tenían del mundo (Mignolo, 2007: 33), o, con otras palabras, "la matriz colonial del poder -o capitalismo tal como lo conocemos en la actualidad- $y$ la modernidad en tanto ideología imperial de Europa" (Mignolo, 2007: 69), América Latina ha sido producida como tienda de oportunidades, "explotada por los Estados imperiales de la actualidad (Estados Unidos y los países imperiales de la Unión Europea) se construye alrededor de la noción de que el subcontinente es un territorio extenso y una fuente de mano de obra barata, con abundantes recursos naturales y destinos turísticos exóticos con hermosas playas caribeñas, una región que da la bienvenida a viajeros, inversores y explotadores" (Mignolo, 2007: 118).

Siguiendo con Mignolo, la geopolítica de la epistemología es la desigual distribución del conocimiento y la geopolítica de la economía lo es de la riqueza (Mignolo, 2007: 68). Del mismo modo podríamos decir que la geopolítica del derecho es la desigual distribución de garantías institucionales. En este marco de desigual distribución, Boaventura de Sousa Santos planteó en el año 2002 la pregunta: ¿puede el derecho ser emancipatorio? Lo primero que debemos señalar es qué entiende Sousa Santos por derecho. Lo define como

"un cuerpo de procedimientos regularizados y estándares normativos que se considera exigible -es decir, susceptible de ser impuesto por una autoridad judicialen un grupo determinado y que contribuye a la creación, prevención y resolución de disputas a través de discursos argumentativos unidos a la amenaza de la fuerza". (Santos, 2009: 56)

2 Es importante el papel que ha tenido el uso alternativo del derecho en Brasil (Souza, 1999). 
Pero más que plantear una definición propia de un teórico del derecho, lo que realiza el autor luso es señalar una necesidad, a saber: es preciso ampliar la visión reductora que del derecho se ha impuesto desde la teoría política liberal que aúna Estado, Nación y derecho desde los postulados del positivismo jurídico decimonónico, por lo que solo se reconocería la escala nacional como eje central y centralizador del derecho (Santos, 2009: 54).

Para ampliar esta visión, recurre a la idea del pluralismo jurídico. Se trata de un pluralismo que escapa de la lógica centralizadora del Estado-nación, reconociéndose así otros órdenes normativos más allá del Estado y que interactúan entre sí. De ahí que señale la existencia de tres escalas (local, nacional y global), donde se dan tres componentes en mayor o menor medida (retórica, burocracia y violencia) y seis espaciostiempo (doméstico, producción, comunidad, mercado, ciudadanía, mundial) (Santos, 2009: 57-63). Esta visión del derecho sitúa a Boaventura de Sousa Santos en lo que llama posmodernismo de oposición: "es posible y necesario pensar en la regulación social y en la emancipación más allá de los límites impuestos por el paradigma de la modernidad. Para lograrlo, se necesita una teoría posmoderna de oposición de la ciencia y del derecho" (Santos, 2009: 43). No se trata de pensar las alternativas, sino "una forma alternativa de pensar alternativas" (Santos, 2005: 106) que pone bajo la crítica las promesas incumplidas de la modernidad (frente a la idea del proyecto inacabado de Habermas). Esta oposición se realizará contra los tres pilares sobre los que se asienta el derecho moderno: "el derecho como monopolio del Estado y como construcción científica; la despolitización del derecho a través de la distinción entre Estado y sociedad civil; y el derecho como principio e instrumento universal de la transformación social políticamente legitimada" (Santos, 2009: 47). Es por ello su apuesta por el pluralismo jurídico (contra el primer pilar), por los seis espacios-tiempo estructurales antes señalados (contra el segundo pilar) y por una repolitización del derecho que impida que la emancipación sea absorbida por la regulación (contra el tercer pilar).

En definitiva, la tarea científica y política en un sistema-mundo que impone globalmente la tradición jurídica occidental es la siguiente: "cómo reinventar el derecho más allá del modelo liberal y demosocialista sin caer en la agenda conservadora y, en efecto, cómo conseguirlo para combatir esta última de una manera más eficiente" (Santos, 2009: 547). Para ello es preciso acudir a las concepciones y prácticas subalternas que sean (1) parte de la tradición occidental pero fueron suprimidas o marginadas, (2) que no pertenezcan a la tradición occidental o (3) que provengan de organizaciones y movimientos de la contrahegemonía global (Santos, 2009: 551). En definitiva, un cosmopolitismo subalterno e insurgente como forma política y cultural de la globalización contrahegemónica (Santos, 2009: 568).

Este cosmopolitismo subalterno e insurgente necesitará resignificar las categorías jurídicas para poder emerger (sociología de las emergencias) (Santos, 2006: 1341) en una globalización hecha desde abajo ${ }^{4}$. La legalidad cosmopolitica subalterna tiene como objetivo de inicio la profundización en la globalización contrahegemónica para poder realizar el fin de la emancipación. Esto es, la construir la globalización contrahegemónica es una necesidad para la emancipación social. Es por ello que la

3 Boaventura de Sousa Santos se centra en el movimiento zapatista como ejemplo de cosmopolitismo subalterno e insurgente (Santos, 2009: 568-573). Con más detalle, Pelayo González-Torre (2019: 109-150).

4 Boaventura de Sousa Santos contrapone la globalización desde arriba o hegemónica (localismos globalizados y globalismos localizados) y la globalización desde abajo o contrahegemónica (Santos, 2009: 307-315). 
posibilidad de respuesta afirmativa a si el derecho puede ser emancipatorio pasa por la construcción de esta legalidad cosmopolitica contrahegemónica. Para ello, Sousa Santos señala ocho tesis (Santos, 2009: 575-581): 1) "una cosa es utilizar una herramienta hegemónica en una determinada lucha política. Otra cosa es utilizarla de una manera hegemónica"; 2) "el uso no hegemónico de herramientas jurídicas hegemónicas reposa en la idea de integrarlas en movilizaciones políticas más amplias que puedan incluir acciones tanto legales como ilegales"; 3) las formas de derecho no hegemónico no favorecen o promueven necesariamente el cosmopolitismo subalterno"; 4) "la legalidad cosmopolita es voraz en cuanto a las escalas de legalidad"; 5) "la legalidad cosmopolita es una legalidad subalterna que tiene como objetivo la sociedad civil incivil y la sociedad civil extraña"5; 6) "como forma de legalidad subalterna el cosmopolitismo somete los tres principios modernos de regulación a una hermenéutica de sospecha"; 7) el vacío entre el exceso de sentido y el déficit de desempeño es inherente a una política de legalidad. La legalidad cosmopolita está preocupada por este vacío"; y 8) "a pesar de las profundas diferencias entre la legalidad demoliberal y la legalidad cosmopolita, las relaciones entre ellas son dinámicas y complejas".

A partir de estas ocho tesis se podría dar esa respuesta afirmativa a la posibilidad emancipatoria del derecho. Una posibilidad que rellene el vacío dejado por las políticas socialistas. Pero este vacío no puede ser colmado con la política y el derecho de la hegemonía liberal, sino por medio de una legalidad cosmopolitica subalterna y contrahegemónica que vaya más allá del Estado-nación como centro de producción normativa y acuda a una constelación de luchas y resistencias. Un ejemplo es cómo construir unos derechos humanos no desde arriba, sino desde abajo (Santos, 2009: 513).

Una visión desde arriba, desde el norte, es aquella que entiende los derechos humanos como universales, lo que implica la posibilidad de imposición norte-céntrica (imperialismo) frente a cualquier otra posible concepción (epistemicidio jurídico). Por el contrario, una visión desde abajo, desde el sur, no plantea su universalidad sino su multiculturalidad o, mejor, su pluriversidad, haciendo salir del otro lado de la línea abismal a los ur-derechos que el colonialismo occidental y la modernidad capitalista relegaron a las ruinas a partir de las cuales se edificaron las catedrales de los derechos humanos (Santos, 2009: 534). Por tanto, una sociología de las emergencias jurídicas parte de aquello que ha sido negado y aquellos que han sido negados.

Esta concepción de los derechos humanos desde lo que ha y desde quienes han sido anulados implica una resignificación radical desde el silencio de la negación. Esta resignificación, plantea Boaventura de Sousa Santos, puede articularse sobre una genealogía abismal de los derechos humanos: derecho al desarrollo frente a la degradación ambiental; cosmovisiones colectivas frente a derechos individuales; derechos humanos frente a derechos de la naturaleza. Estos articularían dignidades posabismales en las que la naturaleza tendría un papel clave (Santos, 2019: 35-58).

\section{Un cambio de perspectiva en la pregunta}

Desde la propuesta planteada por Boaventura de Sousa Santos y teniendo presente la experiencia italiana, pensamos que la pregunta al menos debe ser reformulada.

5 La sociedad civil extraña es aquella que goza de derechos civiles y políticos (inclusión en el sistema) pero que tienen poco acceso a derechos sociales, económicos y culturales (exclusión del sistema). La sociedad civil incivil, por su parte, está compuesta por quienes están totalmente excluidos (Santos, 2009: 564). 
La cuestión no radica en plantear un uso alternativo del derecho en otros espacios geográficos. Las propuestas alternativas del derecho presuponen la existencia de un sujeto que produce una obra. Juan Carlos Rodríguez nos da algunas claves. Su libro Teoría e historia de la producción ideológica comienza con su conocida tesis: "la literatura no ha existido siempre" (Rodríguez, 1990: 5). La literatura no ha existido siempre porque es el producto histórico de una serie de condiciones también históricas, derivadas del nivel ideológico de la modernidad. La literatura, el derecho o la ciencia son discursos. Y un discurso se caracteriza por ser obra de un autor.

Por tanto, la radical historicidad de la literatura lo que nos señala es el punto de emergencia ${ }^{6}$ de un sujeto que produce una obra llamada literatura y que, a diferencia de otros discursos, lo que plantea es una verdad interior. He aquí la lógica del sujeto (moderno) que se contrapone a la del siervo (feudal). La matriz ideológica moderna o burguesa transforma al siervo en proletario (sujeto libre poseedor, al menos, de su propia verdad interior: su fuerza de trabajo). Por tanto, "la literatura surge cuando surge la lógica del sujeto, pero decimos también, y esto es lo decisivo, que tal lógica del sujeto no es otra cosa que una derivación -una "invención" de una matriz ideológica determinada" (Rodríguez, 1990: 8).

La lógica del sujeto hace de este un individuo libre, autónomo, consciente, pensante, razonable, responsable. Cogito, ergo sum. Este Yo soy no hubiese sido posible en el marco de las relaciones feudales. Allí la lógica del siervo haría imposible las relaciones mercantiles, pues se encontraba íntimamente adherido a una tierra y a un señor. Por eso el sujeto moderno hunde su raíz en la matriz ideológica burguesa. Esta necesita convertir al siervo en proletario, esto es, en sujeto libre, igual y poseedor de su fuerza de trabajo. Aquí el posesivo es fundamental: no se trata de la fuerza de trabajo del señor, al fin y al cabo propietario de sus siervos, sino de la fuerza de trabajo que deriva directamente del cogito, de la capacidad de pensar y de pensarse. En tanto propietario de sí mismo, este sujeto de la Modernidad se vende a cambio de un salario. Por eso el sujeto cartesiano es capaz de separar el yo racional de su propio cuerpo, pues es un yo dispuesto para su disciplinamiento. No obstante este cambio, tanto la ideología feudal como la burguesa comparten un mismo patrón: la dominación jerárquica. Si el siervo pertenece al señor, el sujeto libre e igual de la Modernidad se articula en torno a la lógica de las clases: dominantes y dominados. Dejemos que hable de nuevo Juan Carlos Rodríguez:

"En una palabra: el sujeto es una invención de la matriz ideológica burguesa, pero ésta a) lo traslada a todas las épocas; b) trata de hacerlo pasar por una realidad tanto a nivel político o económico como a nivel "eidético" o "espiritual" (por emplear los términos que tal ideología usa) al hablar, por ejemplo, del sujeto jurídico o del sujeto literario. c) Ello no impide, por supuesto, que los discursos jurídicos o los literarios se estructuren, en el ámbito burgués, a partir de la temática del sujeto; lo único que nosotros queremos hacer ahí es mostrar que tal temática sólo existe en tanto que "histórica", es decir, en tanto que trasunto directo de la ideología burguesa de base". (Rodríguez, 1990: 14-15)

La lección que podemos extraer, tanto de la tesis de Juan Carlos Rodríguez como las ya apuntadas de Michel Foucault, gira en torno a un sujeto soberano en su conciencia y en sus actividades. Tanto es así que la era de los derechos solo es posible en tanto el sujeto se hace soberano de sí. Pero, al final, se trata de un ser asimismo sujetado en un doble sentido. Por un lado, sujetado a otro: aquí entran en juego los expertos, los especialistas (médicos, juristas, peritos, psicólogos, psiquiatras,

6 Se utiliza esta palabra según Foucault (1992). 
pedagogos, etc.) y las instituciones (familia, escuela, psiquiátrico, cárcel, quirófano, etc.). Por otro lado, sujetado a sí mismo: la constante construcción obsesiva de la identidad ante la cual queda atado y maniatado.

Dicho esto, la pregunta queremos replantearlas de la siguiente forma: al otro lado de la línea abismal, ¿puede el derecho ser usado? La pregunta implica un espacio (más allá de la línea abismal), una no-subjetividad (la que habita ese otro lado de la línea) que usa (concluiremos este artículo con este verbo que trata de situarse en otra vía a la del uso alternativo del derecho) una obra producida por un sujeto en el aquí de la línea abismal. Y ese uso por el no-sujeto tendrá una finalidad: devenir sujeto, romper la línea abismal. Por tanto, no se trata de emancipación, sino de existencia. No se trata de dejar de estar en el sur y ser norte. Se trata de que la propia existencia trastoque el verbo.

Por eso preguntarnos por la emancipación es una cuestión anclada en las categorías modernas con las que el propio Santos trata de romper. Esta es una crítica que ya Walter Mignolo le hace a Enrique Dussel, pues el concepto emancipación "pertenece al discurso de la ilustración Europea y sigue siendo usado hoy en la misma tradición" (Mignolo, 2010: 19), lo que impide o dificulta el cuestionamiento de la lógica colonial. Es por ello que sea más preciso hablar de liberación, como hiciera Dussel en Filosofía de la liberación, en tanto remite a los proyectos de descolonización epistemológica, política y económica. Pues al final de lo que se trata es de "liberarse de la matriz colonial de poder que sujeta a ambos el colonizador y el colonizado" (Mignolo, 2010: 23).

Dialogar, expresarse, desde unas condiciones materiales discursivas pertenecientes a la lógica colonial, como es el término emancipación, nos hace perder de vista la necesidad de desprendernos de dicha lógica. Pero el concepto liberación también mantiene una posición ambivalente con esta: "emancipación captura el momento en que una etno-clase emergente, la burguesía, se emancipaba de las estructuras monárquicas de poder, en Europa. El concepto liberación, por otra parte, captura la diversidad racializada de etno-grupos colonizados por las burguesías que se emanciparon de las monarquía" (Mignolo, 2010: 27). De ahí que el concepto liberación se mantenga en un locus moderno. Por eso la apuesta de Mignolo es por el concepto descolonialidad en tanto subsume liberación y descolonización.

En otro texto de Santos, publicado en 2018 (Santos, 2018a: 279-316), aunque siga utilizando el verbo emancipar lo hace a partir de ocupar. Su conclusión es desalentadora: "Las revueltas de la indignación parecen indicarnos que no existen las condiciones para la movilización jurídica emancipadora, o que se están deteriorando de tal manera que la movilización política debe dejar de articularse con la movilización jurídica" (Santos, 2018a: 302). No existen, por tanto, condiciones para un derecho contrahegemónico. De ahí que "solo se puede recuperar el derecho como instrumento emancipador si se refunda, y en cierto modo se reinventa, la democracia" (Santos, 2018a: 303).

La pregunta por el derecho, en definitiva, nos lleva a la cuestión del sujeto político capaz de articularse como comunidad. La pregunta por la emancipación ha de ser articulada sobre la pregunta por la existencia y la respuesta a la existencia nos lleva a la ocupación y, como veremos, al uso del derecho. Emancipar, liberar, descolonizar, ocupar, usar. La cuestión última es si el derecho tiene encaje en estos verbos y qué tipo de encaje. 


\section{4. ¿Qué derecho?}

El derecho no ha existido siempre. Esta afirmación también la podría haber escrito Juan Carlos Rodríguez, como antes vimos con la literatura. Plantear que el derecho no ha existido siempre supone preguntarnos por el sujeto que crea la obra derecho y por la matriz ideológica moderna que naturaliza su existencia, como si siempre hubiera existido sujeto y derecho.

Lo que aquí planteamos como hipótesis a partir de la cual pensar la relación entre descolonialidad y derecho, es que este último emerge precisamente con la modernidad $^{7}$. Ya hemos defendido en otros espacios (García López, 2013) que son tres los elementos que constituyen la modernidad jurídica: el Estado, el sujeto de derecho y el capitalismo. Se trata de unos cambios topológicos que definieron una nueva episteme. Emerge el Estado como monopolizador de la producción jurídica, como única fuente del derecho, pasando por un primer momento de razón de Estado hasta llegar al imperio de la ley, paralelo a un proceso de secularización que sustituyó la legitimación divina por la tríada contrato-poder constituyente-constitución (Grimm, 2006; Meinecke, 1983; Naef, 2005). Pero el Estado surgirá a la par que el capitalismo y su fe en el progreso como forma de disolución de los viejos vínculos comunitarios. La sociedad deviene un instrumento para el mercado autorregulador (Polanyi, 1997). Un mercado que necesitará, a su vez, de la abstracción jurídica (Schiavone, 1982: 107-108) y de la razón instrumental que sitúe la calculabilidad en el centro (Tapia Argüello, 2018: 97-101). Es así que el tercer elemento de este ambiente moderno cobra sentido: el sujeto jurídico, portador de derechos y no privilegios, que entrega su libertad a la autonomía del sistema económico (Barcellona, 1996). Y una fecha clave para entender estos tres elementos fue 1648. En aquel año se firma el Tratado de Westfalia que pone fin a la Guerra de los Treinta Años pero también al imperio como vieja forma de universalidad. Como señala Foucault (2008: 277),

"por fin se reconoce que el imperio no es la vocación última de todos los Estados, no es ya la forma esperada o soñada en la cual los Estados se fundirán algún día. Y en la misma época, siempre con el Tratado de Westfalia, se constata por una parte que la fractura de la Iglesia provocada por la Reforma ya es un hecho adquirido, institucionalizado y reconocido, y por otra que los Estados, en su política, sus decisiones, sus alianzas, ya no deben agruparse de acuerdo con su pertenencia religiosa".

Lo que plantea Foucault es cómo estos dos universales, el Imperio y la Iglesia, pierden su sentido. No obstante, la vocación imperial se sustituye por la vocación colonial, de dominación. En cierto modo así lo atisba Foucault cuando señala que "cualquier Estado como España, siempre que tenga los medios, siempre que tenga la extensión, siempre que pueda realmente definir la pretensión, va a procurar ocupar una posición dominante con respecto a los otros. Ya no se aspirará directamente al imperio, sino a una dominación de hecho sobre los restantes países" (Foucault, 2008: 279).

Por lo tanto se construye otro universal para legitimar esa dominación, a saber: el derecho. Es cierto que el término se ha utilizado para referirse a realidades anteriores a la modernidad, pensemos en el derecho romano. Pero habría que plantearse, siguiendo lo visto en el epígrafe anterior, si por derecho solo podríamos referirnos a aquel instrumento de dominación que requiere de un sujeto que lo produzca como una verdad interior (que se externaliza performativamente, cambiando la realidad) en

7 Sobre la relación entre Estado y colonialidad, véase García Fernández (2019: 155-192). 
las condiciones ambientales señaladas. Y es que sobre el derecho la matriz ideológica moderna ha (re)construido un mito fundacional: ubi societas, ibi ius. El derecho existiría en todos los lugares, lo que escondería su vocación de dominación colonial. Se presenta así como un universal atemporal produciendo, parafraseando a Wallerstein, un sistema-mundo jurídico.

Ubi societas, ibi ius es un mantra que repiten desde el primer día de clase en una Facultad de derecho. Donde hay sociedad, hay derecho se ha trasmitido de generación de juristas en generación, sin crítica ni resistencia. Donde hay sociedad, hay derecho es un instrumento de perpetuación ideológica que impide cualquier visión diferente e inmuniza la reproducción del sistema. Como ha sostenido Juan-Ramón Capella, "los juristas suelen identificar así la sociedad humana con la sociedad organizada políticamente. Y trasladan a esta última un atributo que sólo puede predicarse de la primera: la naturalidad de la sociabilidad" (2006: 19). ¿Qué es lo que esto provoca? La imposibilidad de imaginar una sociedad en la que no existan derecho o Estado. Toda relación debe ser previsible y calculable. Este es uno de los postulados de la matriz ideológica moderna: naturaliza los conceptos, contingentes e históricos, como si siempre hubiesen existido, ya sea el derecho, el sujeto o la literatura. Este horror al vacío jurídico es "de la época en que las relaciones mercantiles tienden a sustituir a cualquier otra relación entre los seres humanos. Y expresa el temor a la aparición de cabos sueltos en el tráfico de mercancías" (Capella, 2006: 21). Este aforismo funcionaría como una suerte de hybris del punto cero ${ }^{8}$ : un punto de vista que no admite ser un punto de vista que ha sido narrado como único punto de vista válido, creando la ilusión de un conocimiento universal que se enuncia desde un sujeto deshistorizado y descorporalizado. Tanto es así que el texto jurídico romano más importante en términos epistemológicos, la Ley de las XII Tablas, fue una invención, una ficción que nunca existió (Fögen, 2013; Guarino, 1994: 87-105).

El derecho como universal legitimador de la dominación queda estrechamente ligado al colonialismo. Es el instrumento que permite mantenerlo vivo en la colonialidad. Porque el derecho producirá un tipo de colonialidad del saber (performatividad, verdad, veredicto, veridicción), de poder (jurisdicción, imperio de la ley) y de ser (subjetivación, ciudadanía). El derecho moderno ha sido construido desde una cosmovisión colonial en el que solo una raza, un sexo, una clase, una corporalidad o una edad son legítimas portadoras de sus garantías, naturalizándolas para evitar así crítica y resistencia ${ }^{9}$. El resto, aquellas subjetividades que no encajen en la norma, quedarán en el lado oscuro. No obstante, poco a poco algunas de estas otras subjetividades son incorporadas al lado visible del derecho gracias a un pacto con el norte, pero a costa del despojo de derechos de las subjetividades otras. De ahí que si se quiere luchar contra los tres tipos de colonialidad, hay que reapropiarse del instrumento que los mantiene, manipular el dispositivo del derecho (García López, 2020) como espaciocentro en el que se ubican ser, saber y poder. Porque no puede olvidarse que el derecho es "una violencia a la violencia por el control de la violencia" (Esposito, 2005: 46).

\section{Matriz de inteligibilidad y colonialidad del derecho}

Lo cierto es que el discurso jurídico posee un espacio privilegiado tanto en la colonización como en la colonialidad. En la primera supuso la imposición imperial por parte

8 Se toma la idea de Castro-Gómez (2005).

9 El derecho sería una parte muy importante de lo que Grosfoguel ha llamado los cuatro epistemicidios del largo siglo XVI (Grosfoguel, 2013: 31-58). 
de los reinos europeos sobre los territorios conquistados de una estructura y una organización que permitiera y facilitara la extracción de materiales de las colonias para llevarlas al viejo mundo. En la segunda, el derecho se mantuvo incluso con los procesos de independencia para construir los nuevos Estados. El derecho, por tanto, fue clave en la colonialidad. De ahí que quisiéramos hablar aquí de una matriz de inteligibilidad jurídico-colonial.

Se trata de un concepto cercano al de matriz colonial del poder de Aníbal Quijano, aunque quisiéramos reformularla desde la analogía con los estudios queer de manos de Judith Butler. Planteó el término matriz de inteligibilidad heterosexual como "that grid of culture intelligibility through which bodies, genders, and desires are naturalized" (Butler, 1990: 292). Esto es, se trata de un modelo normativo hegemónico de inteligibilidad del género, de tal forma que se exige coherencia en los cuerpos por medio de la estabilidad de un único sexo expresado en un único género estable (masculino $=$ hombre; femenino $=$ mujer), "that is oppositionally and hierarchically defined through the compulsory practice of heterosexuality" (Butler, 1990: 282). Sexo anatómico, género, deseo y prácticas sexuales deben quedar unidas de forma coherente y estable.

De lo que se trata es de construir una unidad corporal identitaria aceptable, es decir, inteligible, por medio del control constante en nombre de un hipotético bien común. Quienes escapan de la matriz de inteligibilidad son aquellas en las que no se da coherencia y estabilidad. Aquí es importante la idea de código normativo. La matriz de inteligibilidad heterosexual es un discurso regulador que organiza al ser humano en torno al sexo, género, deseo y prácticas sexuales. El código naturaliza al sujeto que cumple con sus normas. $Y$ de igual forma que ocurre con los códigos legales, la matriz de inteligibilidad heterosexual también posee una función preventiva y una función sancionadora para construir (performar) la realidad corporal como una realidad universal y natural, a pesar de ser una imposición artificial. Se trata de una ficción reguladora por la que se presenta como una realidad a la que se remiten las normas que en verdad es creada por estas mismas normas. Es decir, la matriz de inteligibilidad heterosexual funciona de tal forma que da a entender que reproduce una realidad exterior a ella con la que se correspondería (naturalidad; verdad como correspondencia), aunque realmente produce esa realidad (se auto-corresponde) (Winter, 2020).

La matriz de inteligibilidad jurídico-colonial funcionaría al modo de la línea colonial ontológica, con algunas diferencias. Nelson Maldonado-Torres ha planteado este segundo concepto como un

"referente central para entender adecuadamente la profundidad de los retos afrontados por los Derechos del Hombre y las conexiones entre las declaraciones de los derechos humanos y la colonialidad [...]. La línea colonial es la expresión más básica y primaria de la colonialidad, entendida como la producción de diferencias ontológicas organizadas jerárquicamente en formas coloniales como parte del orden civilizacional moderno [...]. Es responsable de dividir el mundo en zonas más claras, más cercanas a la civilización, y zonas más oscuras, más cercanas al contexto definido por la muerte prematura y la tortura, siendo la tortura peor que la propia muerte". (Maldonado-Torres, 2019: 9)

Pero esta línea supone que hay un sujeto que la ha trazado sobre un territorio previo a la línea y esta línea es estática, solo cambiaría si el sujeto decide cambiarla. En cierta forma, la idea de línea supone la posibilidad de que los dos mundos se unan. Pensamos que el derecho no funciona así, que el derecho es constitutivamente 
colonial. Por eso preferimos utilizar el concepto matriz, pues implica una visceralidad. Si el derecho es intrínsecamente colonial, no puede ser entendido como una línea situable más acá o más allá, dependiendo de quien la trace. El derecho es visceralmente colonial: no produce dos mundos, sino un único sistema-mundo que destruye el resto de posibilidades porque el derecho en la matriz necesita inevitablemente expandirse, espacial y temporalmente, para seguir vivo. La vocación del derecho, como la de la matriz, es la de engendrarse a sí mismo de forma permanente, para seguir expandiéndose. Su mejor ejemplo: Lebensraum (espacio vital) y ubi societas ibi ius.

Ese derecho que hemos planteado surge en el siglo XVI con el entramado colonialcapitalista-estatal, dejará tal impronta que actualmente mantiene viva la relación imperial entre el viejo y el nuevo mundo. Plantear la pregunta por la emancipación o por la descolonización no puede dejar atrás al fenómeno jurídico. Es por ello que aquí queramos resaltarlo y hablar de una especificidad en la colonialidad del derecho (Garzón López, 2018: 206-214; Lerussi y Sckmunck, 2016: 7-87). ¿Por qué hacer del derecho una categoría específica en la idea de colonialidad? ¿Qué tiene el derecho que no tenga la literatura, por ejemplo? Porque el derecho funciona con una lógica inmunitaria que hace que la democracia pueda ser suspendida ${ }^{10}$, de tal forma que se dé forma legal a lo que no puede tener forma legal (estado de excepción). De ahí que tanto la forma del colonialismo como la forma de la colonialidad (del ser, saber y poder) nos lleven al derecho: subjetivación, veridicción, jurisdicción. Son formas creadas en el norte jurídico para ser impuestas en el resto del mundo revistiéndose de la neutralidad en tanto el derecho también se posiciona como ciencia centralizada que excluye una posibilidad otra de producción jurídica (Araújo, 2015).

No se trata de una simple huella o una herencia de la que podamos desheredarnos o borrar las marcas, sino de un aspecto constitutivo de la modernidad. Así que si se pretende pensar desde el posmodernismo de oposición, hay que situar al derecho en el centro de la diana. Porque si bien la colonia desapareció, el modo de organizar la comunidad mediante la ley permaneció. Mas también permaneció el carácter imperial del derecho moderno. Mientras los pueblos latinoamericanos se constituían en Estados independientes, en Europa se instauraban nuevas formas de producir, interpretar y aplicar el derecho que pronto fueron impuestas a esos nuevos Estados. Por lo que la raíz imperial del colonialismo se mantiene hasta nuestros días en el campo del derecho, continuando con la producción de una línea abismal en la que se produce un no-existente: la justicia indígena situada (Lerussi y Sckmunck, 2016: 74) ${ }^{11}$. Porque, como se ha planteado antes, uno de los rasgos del derecho moderno es la producción de un sujeto jurídico. Este no es anterior al derecho, sino su efecto. Por lo que toda subjetividad que no haya sido producida por el derecho no podrá interpelar ni interpelarse en la comunidad mediada por la ley. Es por ello que, ampliando la idea de Mignolo, Latinoamérica es una producción colonial pero incluso los sujetos que componen Latinoamérica son una producción de la colonialidad del derecho. Lo que podemos plantear, entonces, es que si, en palabras de Maldonado-Torres, "el colonialismo precede a la colonialidad, la colonialidad sobrevive al colonialismo" (Maldonado-Torres, 2007: 131), en el campo del derecho es cierto que no existe a día de hoy el colonialismo strictu sensu ${ }^{12}$ pero se siguen produciendo categorías

10 Es lo que planteaba el mismo Hans Kelsen al final de Esencia y valor de la democracia.

11 El nuevo constitucionalismo latinoamericano está tratando de abrir precisamente la vía opuesta a través del reconocimiento de esas subjetividades que habían sido históricamente negadas. Véase Salazar Ugarte: 2013 o Milian Nebot: 2018.

12 Salvo el caso clamoroso de Puerto Rico (Atiles-Osoria, 2016; Atiles-Osoria, 2019). 
y formas de entender el derecho que se imponen colonialmente en Latinoamérica desde Europa.

De lo que se sigue una contradicción: usar el derecho como vía de emancipación es solicitar al derecho la existencia como subjetividad, es decir, solicitar ser producido por el propio derecho para poder entrar en la comunidad mediada por la ley. Es decir, se le pide autonomía al Estado y solo el Estado puede garantizar el respeto a dicha autonomía. Esto provoca una tensión entre, por ejemplo, la forma jurídica Estado y las formas de justicia indígena, entre el monolitismo jurídico y el pluralismo jurídico, entre el multiculturalismo liberal y la interculturalidad, entre la nación y la plurinación, entre el pluralismo político eurocéntrico y la democracia intercultural, entre el desarrollo capitalista dependiente y el suma kawsay o suma qamaña (Santos, 2018b: 243-277).

Por eso pensamos que la colonialidad del derecho ha de tener una singularidad propia y no ser introducida en alguna de los otros tipos de colonialidad $^{13}$. Ya que el derecho es una forma de saber, es una forma de poder y es una forma de ser. En el discurso jurídico encontramos entrelazadas la colonialidad del poder, del ser y del saber. El derecho produce sujetos, produce verdades y produce poderes. O por decirlo de otra forma: subjetivación, veridicción, jurisdicción. Además, tal y como están organizadas las sociedades modernas, al ser situado el derecho como el elemento estructurador, es este el que produce el sujeto que producirá a su vez saber. La colonialidad del saber, por ejemplo, no se puede entender sin la colonialidad jurídica y no al revés. Lo que no obsta a que el saber interfiera en el derecho, pero sin el derecho el saber no podría enunciarse.

\section{Conclusiones}

El derecho, en definitiva, al ser construido como un universal de dominación, mantiene abierta la herida colonial. La pregunta queda aún sin responder: ¿es posible usar el derecho para cicatrizar? Quizás la respuesta se halle en un diálogo intercultural, en la traducción, en el mestizaje de saberes, seres y poderes, pero con atención de evitar los peligros de lo jurídico y el refuerzo del colonialismo interno. El debate de Las Casas vs Sepúlveda (1550) sigue vigente. El norte sigue planteando si los pueblos heridos por la colonización y la colonialidad tienen alma propia como para crear su propio derecho, sin pensar en una forma de organización al margen de los parámetros jurídicos. En ese más allá de la línea abismal, el uso plantea su emergencia. Los peligros los conocemos gracias al laboratorio de ese sur que fue la Italia después de la Segunda Guerra Mundial.

¿A qué nos referimos con uso? Aquí las posiciones descoloniales podrían dialogar con Giorgio Agamben. El autor italiano ha propuesto pensar el uso como categoría política fundamental (Agamben, 2014: 47). Aristóteles se refiere en su Política (1254b) a los esclavos como aquellos "cuyo trabajo consiste en el uso del cuerpo" (Aristóteles, 2007: 53). Frente a la naturaleza del hombre libre situada en su capacidad de vivir en el logos, Aristóteles justifica la esclavitud por medio de su remisión al uso del cuerpo. Así el esclavo se encuentra en una zona de indistinción entre instrumento y cuerpo viviente. Lo que hace Agamben es leer a partir de ese uso del cuerpo, trastocando así las ideas centrales para occidente como son la de sujeto y medios y fines.

13 Garzón López, por ejemplo, la sitúa dentro de la colonialidad del saber (Garzón López, 2018: 210). 
En términos jurídicos, la invención de la esclavitud supuso la captura del viviente y del uso del cuerpo en los sistemas productivos. Fue precisamente su abolición lo que permitió el desarrollo de la tecnología (Agamben, 2014: 112). Por eso situar el uso como categoría clave nos permite abrir un paradigma otro de la actividad humana; un uso, además, que queda unido a la idea de inapropiable. Lo que pretende Agamben es desactivar las oposiciones constitutivas del pensamiento occidental: sujetoobjetivo, acto-potencia, esencia-existencia, lenguaje-mundo ${ }^{14}$. Trata de desactivar el derecho entendido como obra, como paradigma de la operatividad.

Pero, ¿por qué el uso? Porque el derecho occidental se ha articulado sobre la idea de propiedad, sobre las relaciones entre las personas y las cosas (Esposito, 2014). La pregunta última es "cómo pensar una forma-de-vida, esto es, una vida humana sustraída del todo a ser capturada por el derecho y un uso de los cuerpos y del mundo que no se sustancia nunca en una apropiación?" (Agamben, 2011: 9-10). Se trata de una vida ligada inseparablemente a su forma. ¿Es posible una zona de indeterminación en la que vida y regla queden unidas y, al mismo tiempo, el derecho sea ajeno? Agamben, por ejemplo, lo sitúa en la estrategia franciscana: abdicaron del derecho al tiempo que separaron uso y propiedad, lo que llamaron pobreza (Agamben, 2011: 139). Esta forma-de-vida aún está por descifrar por el derecho occidental. La altísima pobreza franciscana suponía vivir por fuera del derecho, lo que hacía que ropas, comida u objetos de culto no fuera de su propiedad, sino que solo conservaban su uso en el plano de los hechos, su usus pauper. Esto supuso una clara ruptura con los paradigmas jurídicos del imperio y de la iglesia católica.

De lo que se trata es de articular una relación con el mundo fuera del terrible derecho de propiedad -por usar la expresión de Stefano Rodotà. Porque la relación propietaria es una relación violentamente excluyente. Por eso al situar un afuera del derecho, este se trastoca al no poder abarcarlo todo (Esposito, 2005: 47-48). Como sostiene Agamben (2014: 333-351), la política que viene no puede articularse sobre un poder constituyente que dé lugar a un nuevo derecho, que quede atrapado en las fauces de un poder constituido, igualmente violento, que lo reduzca a la ley. Se trata, por el contrario, de una potencia destituyente por fuera del derecho, una potencia que no desemboque en un poder sino en un devenir permanentemente ingobernables, que deponga el poder tal y como se ha configurado desde la colonialidad, sin fundar uno nuevo. Esta potencia supone resituar las categorías y dejar de pensar el poder como centro bajo el monopolio del Estado. Una potencia destituyente de las vidas desnudas, de la sociedad civil incivil ${ }^{15}$ que nos permitan pensar en una cartografía jurídica pos-abisal (Araújo, 2015). Descolonizar podría ser el infinitivo de esa potencia.

14 Es lo que ha hecho en los diferentes volúmenes que constituyen su obra Homo sacer (19952015), recientemente publicados en su versión integral por la editorial Quodlibet y en los que sitúa el estado de excepción como fundamento del derecho.

15 "La sociedad civil incivil es el círculo externo habitado por aquellos que están completamente excluidos. Son los más invisibles socialmente. Este es el círculo del fascismo social y, en teoría, aquellos que lo habitan no pertenecen a la sociedad civil, puesto que son arrojados al nuevo estado de naturaleza. No poseen ninguna expectativa estabilizada porque en la práctica no tienen derechos" (Santos, 2009: 564). 


\section{Referencias bibliográficas}

Agamben, G. (2011). Altissima povertà. Regole monastiche e forma di vita. Vicenza: Neri Pozza.

Agamben, G. (2014). L'uso dei corpi. Vicenza: Neri Pozza.

Araújo, S. (2015). Desafiando a colonialidade. A ecologia de justiças como instrumento da descolonizaçao jurídica. Hendu, 6, pp. 26-46.

Araújo, S. (2016). O primado do direito e as exclusões abissais: reconstruir a velhos conceitos, desafiar o cânone. Sociologias, 43, pp. 88-115.

Aristóteles (2007). Política. Madrid: Alianza.

Atiles-Osoria, J.M. (2016). Apuntes para abandonar el derecho. Estado de excepción coIonial en Puerto Rico. Puerto Rico: Editora Educación Emergente.

Atiles-Osoria, J.M. (2019). Jugando con el derecho. Movimientos anticoloniales puertorriqueños y la fuerza de la ley. Puerto Rico: Editora Educación Emergente.

Barcellona, P. (1973). L'uso alternativo del diritto. Roma-Bari: Laterza.

Barcellona, P. y Cotturi, G. (1976). El Estado y los juristas. Barcelona: Fontanella, Barcelona.

Barcellona, P. (1996). El individualismo propietario. Madrid: Trotta.

Capella, J.-R. (2005). Los ciudadanos siervos. Madrid: Trotta.

Capella, J.-R. (2006). Fruta prohibida. Una aproximación histórico-teorética al estudio del derecho y del estado. Madrid: Trotta.

Castro-Gómez, S. (2005). La hybris del punto cero. Ciencia, raza e ilustración en la Nueva Granada (1750-1816). Bogotá: Pontificia Universidad Javeriana.

Esposito, R. (2005). Immunitas. Protección y negación de la vida. Buenos Aires: Amorrotu.

Esposito, R. (2014). Le persone e le cose. Torino: Einaudi.

Ferrajoli, L. (1989). Diritto e ragione. Roma-Bari: Laterza.

Fögen, M. T. (2013). La canción de la ley. Madrid: Marcial Pons.

Foucault, M. (1992). Nietzsche, la genealogía, la historia. Valencia: Pre-Textos.

Foucault, M. (2008). Seguridad, territorio, población. Madrid: Akal.

García Fernández, J. (2019). Descolonizar Europa. Ensayos para pensar históricamente desde el Sur. Madrid: Brumaria.

García López, D.J. (2013). Organicismo silente. Rastros de una metáfora en la ciencia jurídica. Granada: Comares.

García López, D.J. (2020). Desterritorializar el dispositivo de la teoría del derecho. Hacia una ontología político-jurídica de la actualidad. Anuario de Filosofía del Derecho, 36, 2020.

Garzón López, P. (2018). Colonialidad (jurídica). Eunomía, 14, pp. 206-214.

Grimm, D. (2006). Constitucionalismo y derechos fundamentales. Madrid: Trotta. 
Grosfoguel, R. (2013). Racismo/sexismo epistémico, universidades occidentalizadas y los cuatro genocidios/epistemicidios del largo siglo XVI. Tabula Rasa, 19, pp. 31-58.

Guarino, A. (1994). II dubbio contenuto pubblicistico delle XII tabole. Pagine di Diritto Romano IV (pp. 87-105). Napoli: Jovene.

Lerussi, R. y Sckmunck, R.A. (2016). Colonialidad del derecho. Sortuz. Oñati Journal of Emergent Socio-legal Studies, vol. 8, 2, pp. 7-87.

Maldonado-Torres, N. (2007). Sobre la colonialidad del ser: contribuciones al desarrollo de un concepto. En Grosfoguel, R. y Castro-Gómez, S. (Eds.). El giro decolonial. Reflexiones para una diversidad epistémica más allá del capitalismo global. Bogotá: Siglo del Hombre.

Maldonado-Torres, N. (2019). De la colonialidad de los derechos humanos. En Santos, B.d.S. y Martins, B.S. (Eds.). El pluriverso de los derechos humanos (pp. 83-107). Madrid: Akal.

Meinecke, F. (1983). La idea de razón de Estado en la Edad Moderna. Madrid: Centro de Estudios Constitucionales.

Mignolo, W. (2007). La idea de América Latina. La herida colonial y la opción decolonial. Barcelona: Gedisa.

Mignolo, W. (2010). Desobediencia epistémica. Retórica de la modernidad, lógica de la colonialidad y gramática de la descolonialidad. Argentina: Ediciones del Signo.

Milian Nebot, X. (2018). El nou constitucionalisme llatinoamericà i la participació política en l'àmbit municipal $i$ comunal veneçolà (1998-2013) com alternativa a l'actual crisi estructural de la democràcia liberal. Tesis Doctoral, Universidad de Valencia.

Naef, W. (2005). La idea de Estado en la Edad Moderna. Granada: Comares.

Negri, T. (1990). El tren de Finlandia. Pliegos de diario 1983. Madrid: Libertarias.

Pasolini, P.P. (2010). Il discorso dei Capelli. En Scritti corsari (pp. 5-11). Milán: Garzanti.

Pelayo González-Torre, A. (2019). La globalización en Boaventura de Sousa Santos. El papel de la epistemología del sur y de América Latina. Derechos y Libertades, 40, pp. 109-150.

Polanyi, K. (1997). La gran transformación. Crítica del liberalismo económico. Madrid: La Piqueta.

Rodríguez, J.C. (1990). Teoría e historia de la producción ideológica. Las primeras literaturas burguesas. Madrid: Akal.

Salazar Ugarte, P. (2013). El nuevo constitucionalismo latinoamericano (una perspectiva crítica). En El constitucionalismo contemporáneo. México: Universidad Nacional Autónoma de México.

Santos, B. de S. (2005). El milenio huérfano. Ensayos para una nueva cultura política. Madrid: Trotta.

Santos, B. de S. (2006). Renovar la teoría crítica y reinventar la emancipación social. Buenos Aires: Clacso.

Santos, B. de S. (2009). Sociología jurídica crítica. Madrid: Trotta. 
Santos, B. de S. (2018a). Para una teoría sociojurídica de la indignación: ¿es posible ocupar el derecho?, en Construyendo las epistemologías del sur, vol. II. Buenos Aires: Clacso.

Santos, B. de S. (2018b). Cuando los excluidos tienen derecho: justicia indígena, plurinacionalidad e interculturalidad, en Construyendo las epistemologías del sur (pp. 243277), vol. II. Buenos Aires: Clacso.

Santos, B. de S. (2019). Derechos humanos, democracia y desarrollo. En Santos, B. de S. y Martins, B.S. (Eds.), El pluriverso de los derechos humanos. La diversidad de las luchas por la dignidad (pp. 35-58). Madrid: Akal.

Schiavone, E. (1982). Historiografía y crítica del derecho. Madrid: Edersa.

Silveira Gorski, H. C. (1998). El modelo político italiano. Barcelona: Universidad de Barcelona.

Souza, M. L. (1999). El uso alternativo del derecho. Génesis y evolución en Italia, España y Brasil. Ed. Universidad de León.

Tapia Argüello, S.M. (2018). Derecho, modernidad y razón. Reformas y nuevo constitucionalismo en América Latina. En Alvarado Rodríguez, M.E. (Ed.), Modernidad y derecho en América Latina: acumulación capitalista, desarrollo, naturaleza y movimientos sociales contrahegemónicos, México: Universidad Nacional Autónoma de México.

Winter Pereira, L. (2020). On Epistemonormativity: From Epistemic Injustices to Feminist Academic Caringzenship. En Murphy, M., Burke, C., Costa, C., Raaper, R. (Eds.), Social Theory and the Politics of Higher Education: Critical Perspectives on Institutional Research. Londres/New York: Bloomsbury.

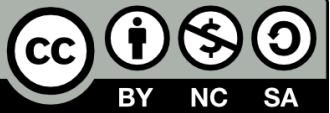

(C) 2021 por el autor. Licencia a ANDULI, Editorial Universidad de Sevilla. Este artículo es un artículo publicado en acceso abierto bajo los términos y condiciones de la licencia Creative Commons Attribution (CC BY) (https://creativecommons.org/ licenses/by-nc-sa/4.0/). 